\title{
A novel in vitro tissue culture approach to study salt stress responses in citrus
}

\author{
Almudena Montoliu · María F. López-Climent • \\ Vicent Arbona · Rosa M. Pérez-Clemente · \\ Aurelio Gómez-Cadenas
}

\begin{abstract}
In citrus, a major crop throughout the world, growth and yield are seriously affected by salinity. ferent approaches, including agronomical, physiological and molecular methods, have been used to address this problem. In this work, an in vitro experimental system has been developed to study the toxic effect of $\mathrm{NaCl}$ on three citrus genotypes, avoiding the ion filter that represents the root system. To carry out the experiments, shoots were obtained from nodal segments of Cleopatra mandarin, Carrizo citrange and citrumelo CPB4475 plants growing in
\end{abstract}

Keywords Oxidative stress · Plant hormones . Stress tolerance $\cdot$ Toxic ions

\section{Introduction}

Salts in the substrate affect plant growth in two ways: First, the presence of salt reduces the ability of the plant to take up water which leads to reductions in the growth rate. This is referred to as the osmotic effect of salt stress, which starts immediately after the salt concentration around the roots increases over a threshold level. There is a second and slower response due to the accumulation of ions in leaves. This ion-specific phase of plant response to salinity starts when accumulated salt reaches toxic concentrations in the leaves (Gómez-Cadenas et al. 1998). Within many species, documented genetic variation exists in the rate of accumulation of $\mathrm{Na}^{+}$and $\mathrm{Cl}^{-}$in leaves, as well as in the degree to which these ions can be tolerated (Munns and Tester 2008). For most species, $\mathrm{Na}^{+}$appears to reach a toxic concentration before $\mathrm{Cl}^{-}$does. However for some species, as in the case of citrus, $\mathrm{Cl}^{-}$is considered to be the more toxic ion (Moya et al. 2002, 2003; López-Climent et al. 2008).

The differences found among citrus rootstocks regarding salt tolerance have been related mainly to their ability to exclude chloride (Bañuls et al. 1997; Moya 2003) although the ability to keep a high performance of the photosynthetic system also seems important (López-Climent et al. 2008). Certain citrus genotypes such as Cleopatra mandarin (CM) or Rangpur lime rootstocks can be classified as relatively tolerant due to their ability to restrict chloride ions to roots while others, such as Carrizo citrange (CC) or citrumelo CPB4475 (Cit), have proved to be more sensitive to salinity (López-Climent et al. 2008). 
Salinity causes suberization of root tissues (Walker et al. 1984), a decrease in root hydraulic conductivity, an impaired assimilation of mineral nutrients (Ruiz et al. 1997), visual toxicity symptoms (Chapman 1968) and eventually leaf abscission (Gómez-Cadenas et al. 1998, 2002). Furthermore, chloride accumulation in citrus leaves decreases net photosynthetic rate, transpiration and stomatal conductance while activating plant antioxidant machinery (Arbona et al. 2003; Iglesias et al. 2004).

The analysis of endogenous levels of plant hormones such as abscisic acid (ABA) ethylene, and its direct precursor, 1-aminocyclopropane-1-carboxilic acid, revealed a general pattern of hormonal change composed by a two phase response that paralleled the chloride accumulation in salt-stressed plants (Gómez-Cadenas et al. 1998, 2002). Therefore, ABA and ethylene have been involved as modulators of some of the responses of citrus to high salinity (Gómez-Cadenas et al. 1998).

It has been shown that the root system plays a key role in controlling water and chloride uptake (Moya et al. 2002). An adaptative improvement of the salt-tolerant genotype $\mathrm{CM}$ can be inferred from the linear correlation between chloride and water usage (Moya et al. 2003). It appears that $\mathrm{CM}$ has a more restrictive mechanism than CC for chloride influx at the root level, being highly efficient in limiting chloride uptake to the aerial part (Moya et al. 2002). Since differences are not only restricted to the aerial part or the root system, it is very difficult to study, under conditions, other putative moss, perlite and vermiculite (80:10:10) as a substrate. Plants were watered when needed with a $0.5 \mathrm{~L}$ of a halfstrength Hoagland solution (Bañuls et al. 1997). Three months after germination, salt stress was applied by increasing $\mathrm{NaCl}$ concentration in the watering solution to $90 \mathrm{mM}$. Percentages of salt affected plants, chloride, and malondialdehyde (MDA) contents were recorded at 10, 20 and 30 days of culture.

In a second set of in vitro experiments, greenhousegrown plants of the same citrus rootstocks were used as a source of plant material. Stem pieces (15 cm long) were stripped of their leaves, disinfected by immersion for $10 \mathrm{~min}$ in a $2 \%(\mathrm{v} / \mathrm{v})$ sodium hypochlorite solution containing $0.1 \%(\mathrm{v} / \mathrm{v})$ Tween wetting agent, and rinsed three times with sterile water. Node stem segments $(1 \mathrm{~cm}$ long) were cultured in Petri dishes with basal medium (BM), containing the inorganic salts of Murashige and Skoog (1962), $100 \mathrm{mg} / \mathrm{l}$ i-inositol, $1 \mathrm{mg} / \mathrm{l}$ pyridoxine-HCl, $0.2 \mathrm{mg} / \mathrm{l}$ thiamine- $\mathrm{HCl}, 1 \mathrm{mg} / \mathrm{l}$ nicotinic acid and $30 \mathrm{~g} / \mathrm{l}$ sucrose. The $\mathrm{pH}$ was set at $5.7 \pm 0.1$ with $0.1 \mathrm{~N} \mathrm{NaOH}$ before autoclaving. The medium was solidified by the addition of agar (Pronadisa, Madrid, Spain).

Shoots recovered from nodal stem segments were excised from the explant and cultured into $150 \times 20 \mathrm{~mm}$ tubes on multiplication medium (MM) to promote the development of axillary buds. MM consisted of BM medium supplemented with $0.4 \mathrm{mg} / \mathrm{l}$ 6-benzylaminopurine. During the growth formed from buds located at leaf axils. When these shoots 
collected after 2, 5, 10 and 20 days of the imposition of salt stress and MDA, ABA and salicylic acid (SA) contents measured.

To assess whether the growth regulators used in the culture media had some effect on the results obtained, a new experiment was carried out using the following culture media: BM as control and the same media supplemented with $60 \mathrm{mM} \mathrm{NaCl}$ for the salt treatment, MT and MT2. After 20 days of treatment, percentage of plants affected by salt was recorded and plant material collected for chloride and MDA analyses.

In all cases, plant material was cultivated in culture rooms at $24^{\circ} \mathrm{C}$ with a 16 -h photoperiod. Leaves or shoots were collected, rinsed with distilled water to eliminate any residue and frozen in liquid nitrogen. Plant material was kept at $-80^{\circ} \mathrm{C}$ until further analyses.

\section{Visible symptoms of leaf damage}

The presence of yellowish spots at the leaf tip that progressively led to severe burning injuries was considered to be a good visible estimate of chloride-induced damage to leaves. The number of damaged leaves was regularly recorded during the experimental period and expressed as a percentage of the total number of leaves. Plants or shoots showing a percentage of damaged leaves equal to or over $50 \%$ were considered salt "affected".

\section{Chloride content}

Chloride content was measured by automatic titration as described in López-Climent et al. (2008). Samples were oven-dried for $72 \mathrm{~h}$ at $70^{\circ} \mathrm{C}$. After desiccation, samples were minced and incubated overnight in a $0.1 \mathrm{~N} \mathrm{HNO3}$ (PA grade, Panreac, Barcelona, Spain) and 10\% glacial acetic acid (Baker grade, JT Baker, Barcelona, Spain) solution. After filtering, $0.5 \mathrm{ml}$ of the solution was used for determination in a chloridometer (Model 626, Sherwood Scientific Ltd., Cambridge, UK).

\section{Malondialdehyde concentration}

Malondialdehyde concentration was measured following the procedure described in Hodges et al. (1999). Plant material was homogenized in $5 \mathrm{ml}$ of $80 \%$ cold ethanol (Panreac, Barcelona, Spain) using a tissue homogenizer (Ultra-Turrax; IKA-Werke, Staufen, Germany). Homogenates were centrifuged at $4^{\circ} \mathrm{C}$ to pellet debris and different aliquots of the supernatant were mixed either with $20 \%$ trichloroacetic acid (TCA) (Panreac, Barcelona, Spain) or a mixture of 20\% TCA and 0.5\% thiobarbituric acid (SigmaAldrich, Madrid, Spain). Both mixtures were allowed to react in a water bath at $90^{\circ} \mathrm{C}$ for $1 \mathrm{~h}$. After this time, samples were cooled down in an ice bath and centrifuged. Absorbance at 440, 534 and $600 \mathrm{~nm}$ was read in the supernatant against a blank. The MDA concentration in the extracts was calculated as in Arbona et al. (2008).

Abscisic acid and salicylic acid analyses

Plant hormones were analyzed by HPLC coupled to tandem mass spectrometry as described in Durgbanshi et al. (2005) and Arbona and Gómez-Cadenas (2008). Briefly, frozen citrus shoots were ground to a fine powder with a pre-chilled mortar and a pestle and then $0.5 \mathrm{~g}$ of powdered tissue was extracted in ultrapure water using a tissue homogenizer (Ultra-Turrax, Ika-Werke, Staufen, Germany). Before extraction, samples were spiked with $100 \mathrm{ng}$ of $\left[{ }^{2} \mathrm{H}_{6}\right]-\mathrm{ABA}$, and $100 \mathrm{ng}$ of $\left[{ }^{2} \mathrm{H}_{4}\right]-\mathrm{SA}$. After extraction and centrifugation, the $\mathrm{pH}$ of the supernatant was adjusted to 3.0 and partitioned twice against di-ethyl-ether (Panreac, Barcelona, Spain). The organic layers were combined and evaporated in a centrifuge vacuum evaporator (Jouan, Saint-Herblain, France). The dry residue was thereafter resuspended in a water:methanol (9:1) solution, filtered, and injected into a HPLC system (Alliance 2695, Waters Corp., Milford, USA). Hormones were then separated in a reversed-phase Kromasil 100 C18 column $(100 \times 2.1 \mathrm{~mm}$ $5-\mu \mathrm{m}$ particle size) using methanol and ultrapure water both supplemented with glacial acetic acid to a concentration of $0.05 \%$. The mass spectrometer, a triple quadrupole (Quattro LC, Micromass Ltd., Manchester, UK), was operated in negative ionization electrospray mode and plant hormones were detected according to their specific transitions using a multiresidue mass spectrometric method (Durgbanshi et al. 2005).

Statistical analyses

Data mean comparisons and regression analyses were performed with STATGRAPHICS PLUS v.5.1. (Statistical Graphics Corporation, Herndon, VA) software. One-way ANOVA and comparisons between means were made following the LSD test at $P<0.05$.

\section{Results}

Effect of salt stress on intact plants of different citrus genotypes

In a first experiment, 3-month-old intact seedlings of the three citrus genotypes $\mathrm{CC}$, Cit and CM, were watered with an increased concentration of $\mathrm{NaCl}$ to study the effect of salt stress on young plant material (Table 1). Leaf damage was obvious from the first day of measurement in plants of 
Table 1 Damage, chloride concentration and malondialdehyde (MDA) content in leaves of intact plants of three citrus genotypes subjected to salt stress

\begin{tabular}{|c|c|c|c|c|c|c|c|}
\hline & & \multicolumn{6}{|c|}{ Time of treatment (days) } \\
\hline & & \multicolumn{2}{|l|}{10} & \multicolumn{2}{|l|}{20} & \multicolumn{2}{|l|}{30} \\
\hline & & Control & $90 \mathrm{mM} \mathrm{NaCl}$ & Control & $90 \mathrm{mM} \mathrm{NaCl}$ & Control & $90 \mathrm{mM} \mathrm{NaCl}$ \\
\hline \multirow{3}{*}{$\begin{array}{l}\text { Leaf damage } \\
\text { ( } \% \text { of affected plants) }\end{array}$} & Carrizo citrange & $0.00 \pm 0.00$ & $6.15 \pm 0.04^{*}$ & $0.00 \pm 0.00$ & $12.50 \pm 0.80 *$ & $0.00 \pm 0.00$ & $48.42 \pm 1.91 *$ \\
\hline & Citrumelo CPB 4475 & $0.00 \pm 0.00$ & $12.02 \pm 1.01 *$ & $0.00 \pm 0.00$ & $21.12 \pm 3.29 *$ & $0.00 \pm 0.00$ & $61.08 \pm 1.54 *$ \\
\hline & Cleopatra mandarin & $0.00 \pm 0.00$ & $0.00 \pm 0.00$ & $0.00 \pm 0.00$ & $4.00 \pm 0.42 *$ & $0.00 \pm 0.00$ & $11.64 \pm 0.29 *$ \\
\hline \multirow[t]{3}{*}{$\mathrm{Cl}^{-}$(mg/g fresh tissue) } & Carrizo citrange & $4.14 \pm 0.84$ & $6.32 \pm 0.39^{*}$ & $3.87 \pm 0.65$ & $14.47 \pm 2.09 *$ & $5.11 \pm 0.56$ & $32.19 \pm 0.98 *$ \\
\hline & Citrumelo CPB 4475 & $2.36 \pm 0.64$ & $6.96 \pm 0.80^{*}$ & $2.14 \pm 0.58$ & $18.24 \pm 1.57 *$ & $2.94 \pm 0.20$ & $35.12 \pm 2.67 *$ \\
\hline & Cleopatra mandarin & $1.94 \pm 0.20$ & $2.53 \pm 0.49$ & $1.47 \pm 0.11$ & $4.5 \pm 0.95^{*}$ & $1.53 \pm 0.01$ & $12.61 \pm 0.19 *$ \\
\hline \multirow[t]{3}{*}{ MDA (nmol/g fresh tissue) } & Carrizo citrange & $29.57 \pm 2.15$ & $30.00 \pm 1.58$ & $27.41 \pm 1.21$ & $42.01 \pm 1.29 *$ & $27.78 \pm 2.52$ & $37.56 \pm 2.00 *$ \\
\hline & Citrumelo CPB 4475 & $25.65 \pm 1.92$ & $32.09 \pm 2.19^{*}$ & $23.99 \pm 2.08$ & $51.19 \pm 2.84 *$ & $26.39 \pm 1.90$ & $48.52 \pm 3.25^{*}$ \\
\hline & Cleopatra mandarin & $25.30 \pm 1.81$ & $24.22 \pm 0.33$ & $21.33 \pm 0.63$ & $23.76 \pm 0.88$ & $22.43 \pm 1.32$ & $22.03 \pm 0.50$ \\
\hline
\end{tabular}

* Symbols followed with an asterisk denote statistical significance at $P<0.05$. Data in insets are normalized mean values \pm relative SE

Cit. In this genotype, after 30 days of stress, affected plants were $61 \%$ of the total. Plants of CC also showed evident damage due to the increased concentration of $\mathrm{NaCl}$ from day 10 , being $50 \%$ of the plants affected by the stress at day 30. Contrastingly, the percentage of CM plants affected by salt stress was only $11 \%$ over a 30 -day period. Leaf $\mathrm{Cl}^{-}$concentration mimicked damage and leaves of Cit and $\mathrm{CC}$ plants accumulated the highest concentration of the toxic ion whereas in leaves of $\mathrm{CM}$, chloride content was much lower throughout the experimental period. Basal levels of $\mathrm{Cl}^{-}$were lower in $\mathrm{CM}$ than in the rest of genotypes. Leaf MDA concentration (an indirect marker of saltstress induced oxidative damage) increased in the sensitive genotypes (Cit and $\mathrm{CC}$ ) until a certain extent and then remained constant. In contrast, leaf MDA content in saltstressed plants of $\mathrm{CM}$ was similar to that in control plants throughout the experimental period.

\section{Adjustment of $\mathrm{NaCl}$ concentration in the in vitro system}

Shoots of the CC, Cit and CM cultivated in vitro were subjected to different saline treatments $(30,60$ and $90 \mathrm{mM}$ $\mathrm{NaCl}$ ) and the pattern of $\mathrm{Cl}^{-}$concentration followed over a 30 day period (Fig. 1). Chloride concentration in control shoots showed similar basal values among the three genotypes throughout the experimental period. After salinisation, chloride in shoots progressively increased in all genotypes and for all treatments, being the highest levels found in the most severe salt treatment. Although the studied citrus genotypes exhibited slightly different accumulation patterns (chloride accumulation was faster in CC and $\mathrm{Cit}$ than in $\mathrm{CM}$ ), all tended to similar maximum values (Fig. 1). For the subsequent experiments, $60 \mathrm{mM} \mathrm{NaCl}$ was set as the salt stress treatment because this intermediate concentration did not promote a high mortality (as that observed in shoots treated with $90 \mathrm{mM} \mathrm{NaCl}$ ), but allowed an important and fast $\mathrm{Cl}^{-}$accumulation (higher than in the $30 \mathrm{mM}$ treatment) useful for further measurements.

Effect of salt stress on in vitro cultured shoots of the different citrus genotypes

It is well known that, under field conditions, salinity causes yellowing, bronzing, or browning of leaves and premature foliage drop. In our experimental system, damage caused by exposure of citrus shoots to $60 \mathrm{mM} \mathrm{NaCl}$ was evidenced by the apparition of characteristic leaf symptoms (Fig. 2). It was observed that leaf injury become more severe as the period of salt treatment progressed. After 10 days, light yellowing was observed in all genotypes. Leaf chlorosis increased after 20 days in all the cases and, at the end of the treatment ( 30 days), browning was evident in leaf tissues of all genotypes.

To quantify the occurrence of toxicity due to chloride ions, we considered as affected shoots those showing necrosis in at least $50 \%$ of their leaves. Figure 3 represents the percentage of $\mathrm{CC}, \mathrm{CM}$ and Cit shoots affected by salinity $(60 \mathrm{mM})$ after $0,10,20$ and 30 days of treatment. Leaf damage increased very fast in Cit $(60 \%$ of affected plants vs. $20 \%$ in $\mathrm{CM}$ and $17 \%$ in $\mathrm{CC}$ at day 10). After 20 days of salt treatment, 75 and $66 \%$ of $\mathrm{CC}$ and $\mathrm{CM}$ shoots were damaged respectively whereas almost all Cit shoots showed significant leaf damage. In all cases, and despite the slight different rates of leaf damage occurrence, shoots were in very bad conditions after 30 days of salt treatment (Figs. 2 and 3).

When chloride concentration was determined in shoots of CC, CM and Cit after 10, 20 and 30 days of treatment, no differences were found among the three citrus genotypes (Table 2). The accumulation of $\mathrm{Cl}^{-}$ions took place 


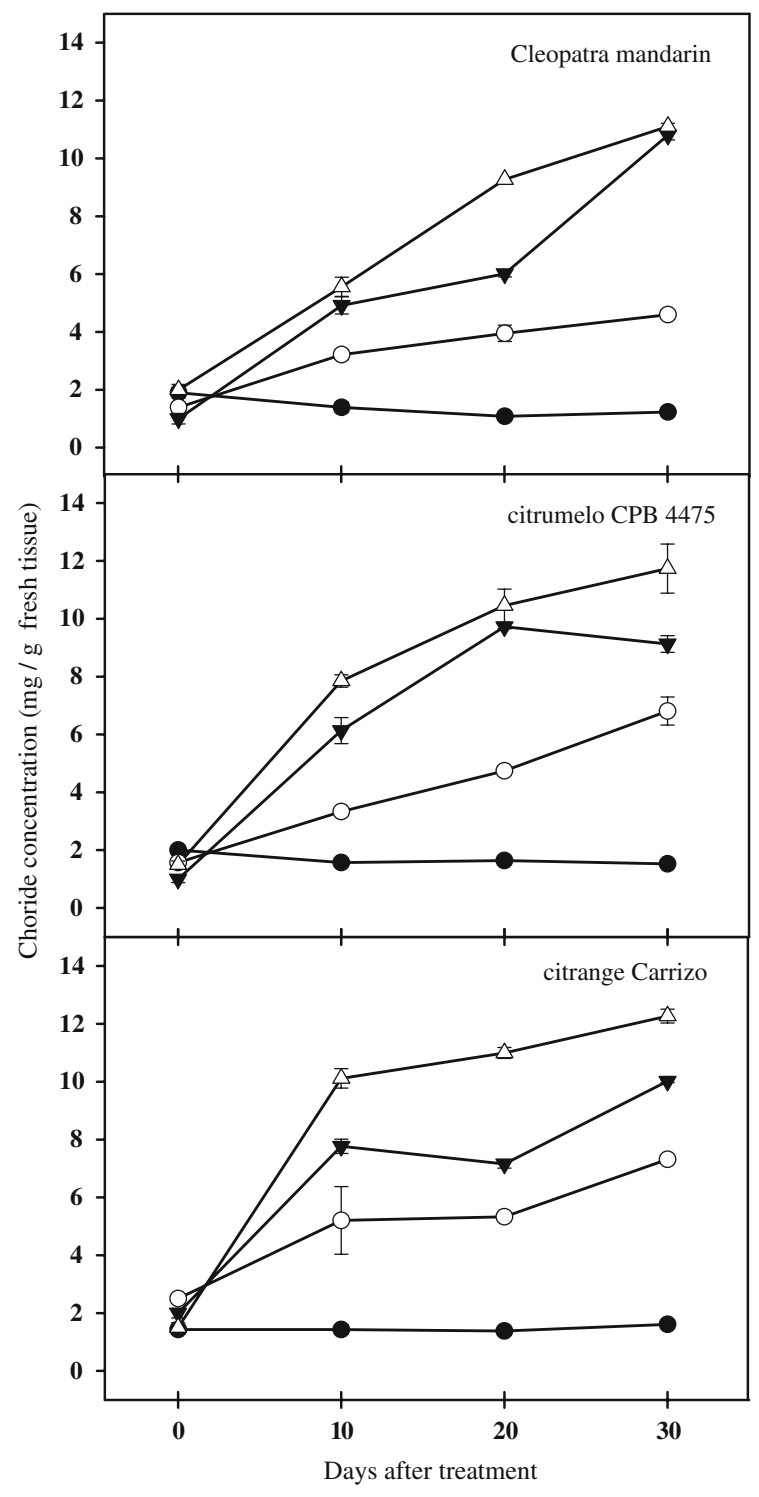

Fig. 1 Shoot chloride concentration in three citrus genotypes subjected to different concentrations of $\mathrm{NaCl}$. In control (filled circle), 30 (open circle), 60 (filled inverted triangle), and 90 (open triangle) $\mathrm{mM} \mathrm{NaCl}$ supplemented medium. Each point corresponds to the average \pm standard error of four independent determinations progressively throughout the experimental period. After 10 days of treatment, values threefold above controls were recorded in salinized shoots (ranging from 6.80 to $8.89 \mathrm{mg} / \mathrm{g}$ in control shoots vs. $20.85-27.00 \mathrm{mg} / \mathrm{g}$ in salinized ones). At the end of the experiment, $\mathrm{Cl}^{-}$concentration in salinized shoots achieved values even higher (ranging from 6.55 to $13.20 \mathrm{mg} / \mathrm{g}$ in control shoots vs. $33.73-39.08 \mathrm{mg} / \mathrm{g}$ in salinized ones).

As an indicator of oxidative damage, MDA content was measured in shoots of citrus genotypes. No significant differences were found between salt-stressed and control shoots of Cit and CM (Table 2). However in CC, $60 \mathrm{mM}$ $\mathrm{NaCl}$ treatment induced reductions in MDA content at day
10 and 30 and a slightly significant increase at day 20 (1.2fold above controls), suggesting a poor correlation between MDA content and leaf damage.

Salt treatment did not induce significant ABA accumulation in shoots of any genotype, regardless the extent of saline treatment (Table 2). ABA contents in control shoots were higher than in stressed ones in all genotypes throughout the experimental period except for a transient increase in salt-treated Cit shoots after 20 days. Elevated SA levels were observed in shoots of all studied genotypes after 10 days of treatment (Table 2), although it was no significantly different in the case of CC. This could evidence an early signaling of SA as a consequence of salt stress.

Early effects of salt stress on in vitro shoots of Carrizo citrange

To investigate the early effects of salt stress, chloride concentration, MDA, ABA and SA contents were measured on in vitro cultured CC shoots 2, 5 and 10 days after the imposition of saline conditions (Table 3). Chloride content remained almost invariable throughout the experimental period in control shoots. On the contrary, chloride concentration in salinized shoots progressively increased with time. Two days after the onset of the treatment, $\mathrm{Cl}^{-}$ concentration in salinized shoots was 1.5 times higher than that found in control ones, and achieved levels 4.6 times higher than in control shoots at day 10 .

No differences in MDA levels were found between control and salinized shoots after short saline treatment periods. However a slight increased of MDA took place at day 10; in comparison with the values obtained at day 2 , in both, control (27.3 vs. $16.48 \mathrm{nmol} / \mathrm{g}$ fresh tissue) and salinized-shoots (29.74 vs. $20.79 \mathrm{nmol} / \mathrm{g}$ fresh tissue).

Abscisic acid content in control shoots was similar to that measured in salinized ones; only after 5 days of saline treatment the differences between them were statistically significant. As observed before, ABA content in control shoots was much higher than in stressed ones (33.20 vs. $9.6 \mathrm{ng} / \mathrm{g}$ fresh tissue).

No differences were found in the content of SA between control and salinized shoots after 2 and 5 days. After 10 days of stress, a slight although no significant increase in this hormone was recorded (Table 3).

Effect of plant growth regulators

To elucidate whether the addition of plant growth regulators to the culture medium had some effect on the studied parameters, changes in foliar damage, chloride and MDA contents were measured after 20 days in CC shoots cultured in medium with or without plant growth regulators 
Fig. 2 Effect of salt stress in different citrus genotypes. Yellowing, browning and necrosis in leaves of Cleopatra mandarin (a), Citrumelo CPB 4475 (b) and citrange Carrizo (c) affected by salinity. In each picture and from left to right: control leaves and after 10, 20 and 30 days of saline treatment. d Necrotic shoot of Cleopatra mandarin after 30 days saline treatment (right) and control (left)

and with or without treatment with $60 \mathrm{mM} \mathrm{NaCl}$ (Table 4). Shoots grown on media, supplemented or not with plant growth regulators, showed the same behaviour. Healthy leaves (without evident damage) were observed in shoots cultured in both media (with or without plant growth regulators, Table 4). This suggests that no additional hormones are required to maintain shoots in vitro for 20 days.

396 Shoots growing in salt-stress conditions showed foliar 397 damage (approximately a 70\% of affected shoots) without 398 significant differences due to the presence of plant growth regulators in the medium.

Similar increases in $\mathrm{Cl}^{-}$concentration were observed in 401 shoots growing in both salinized media $(4.71 \mathrm{mg} / \mathrm{g}$ in 402 media supplemented with plant growth regulators vs. $4035.23 \mathrm{mg} / \mathrm{g}$ in media without them). In the same way, no 404 significant variations in MDA content were observed 405 between plants cultured with additional plant growth reg406 ulators or without them. In this case, as observed before, 407 salt treatment did not modify MDA levels.

\section{Discussion}

409 The literature extensively describes how 


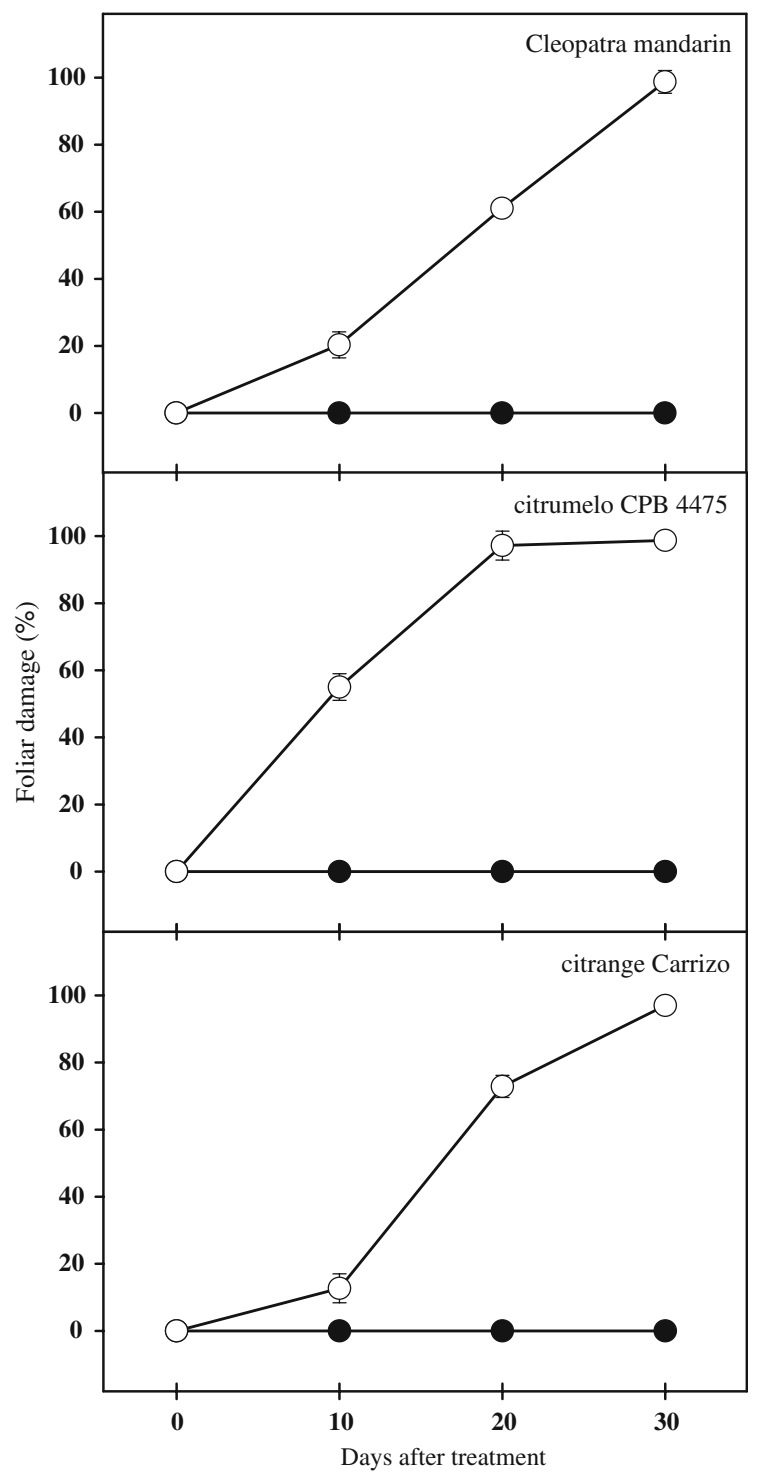

Fig. 3 Percentage of citrus shoots affected by salinity. Shoots were grown in control (filled cirlce) or $60 \mathrm{mM} \mathrm{NaCl}$ supplemented (open circle) medium. Each point corresponds to the average \pm standard error of 18 independent determinations

both salt-tolerant and salt-sensitive genotypes accumu- lating similar amounts of chloride, which is really complicated under field conditions. Therefore, the method proposed appears to be a good tool for studying biochemical processes involved in the response of citrus to salt stress. Singh et al. (2004) cultured calli from different citrus rootstocks differing in their tolerance to salt stress. In this study, a good correlation between salt tolerance and ion accumulation was found. The differences found between both systems must be due to the totally different type of tissue cultured. Furthermore, while the system used by Singh et al. (2004) could be used as a practical tool to evaluate salt tolerance of citrus germoplasm (due to the similar behaviour of calli and intact plants), our system is oriented to elucidate common and specific response to ion toxicity among genotypes, avoiding the root filter. Salt stress tolerance has been correlated with an improved oxidative stress response in several crops (Shalata et al. 2001; Perl-Treves and Perl 2002). Increased MDA levels in leaves of intact plants of $\mathrm{CC}$ and Cit plants were also observed under salt treatment (Table 1). However, no significant differences were found between salt-stressed and control shoots of Cit and $\mathrm{CM}$ (Table 2) when cultured in vitro without root system. In the case of CC, a slight decrease in MDA content was found in some points. From these results, we can conclude that there is no correlation between foliar damage and oxidative stress: characteristic leaf symptoms caused by salinity (yellowing, browning, etc) were observed in all studied genotypes while no consistent MDA accumulation was detected.

Abscisic acid plays a pivotal role in the adjustment of plants to abiotic stress conditions (Gómez-Cadenas et al. 1998; Christmann et al. 2006); it is the long-distance signal that communicates water stress from the root to the shoot. Evidence for root-derived ABA as a long-distance signal has been obtained from split-root experiments with whole plants in which only one part of the root system experienced water deficit (Dodd et al. 2008). Earlier studies showed that, in many crops, the leaf can accumulate ABA in response to salt stress (Montero et al. 1997; Sibole et al. 1998). In the case of citrus, previous reports indicate that the genotype $\mathrm{CC}$ responds to salinity by increasing $\mathrm{ABA}$ levels (Gómez-Cadenas et al. 1998). These experiments were performed with whole intact plants and it is possible that such salt treatment in the roots leads to a shoot water deficit that, in turn, triggers ABA accumulation. These results suggested the existence of an osmosensing mechanism and also the organ-specific nature of such a response. This suggestion is also supported by the fact that gene expression in response to salt stress usually is organ- or tissue-specific (Jia et al. 2002). When shoots were cultured in vitro, no accumulations of ABA were observed in any of the studied genotypes, which seem to discard an $\mathrm{ABA}$ dependent signaling. These results are similar to those obtained in maize by Jia et al. (2002), who observed that $\mathrm{NaCl}$ treatment only induced a small $\mathrm{ABA}$ accumulation in leaf tissues, whereas on the contrary, the same treatment of $\mathrm{NaCl}$ caused a significant ABA accumulation in root tissues.

The transient increase of SA levels at 10 days of salt treatment could suggest a role for this hormone in the response of citrus to salinity. Although further work should be done to understand this effect, our data suggests a common signal not related to genotype tolerance as observed in all studied genotypes, independently of their tolerance to high salinity. 
Table 2 Chloride, malondialdehyde (MDA), abscisic acid (ABA) and salicylic acid (SA) contents in shoots of three citrus genotypes subjected to salt stress $(60 \mathrm{mM} \mathrm{NaCl})$

\begin{tabular}{|c|c|c|c|c|c|c|c|}
\hline & & \multicolumn{6}{|c|}{ Time of treatment (days) } \\
\hline & & \multicolumn{2}{|l|}{10} & \multicolumn{2}{|l|}{20} & \multicolumn{2}{|l|}{30} \\
\hline & & Control & $60 \mathrm{mM} \mathrm{NaCl}$ & Control & $60 \mathrm{mM} \mathrm{NaCl}$ & Control & $60 \mathrm{mM} \mathrm{NaCl}$ \\
\hline \multirow{3}{*}{$\begin{array}{l}\mathrm{Cl}^{-} \\
\quad \text { (mg/g } \\
\quad \text { fresh tissue) }\end{array}$} & Carrizo citrange & $7.70 \pm 0.02$ & $27.00 \pm 0.04^{*}$ & $6.06 \pm 0.02$ & $30.25 \pm 0.04 *$ & $13.20 \pm 0.02$ & $33.73 \pm 0.05^{*}$ \\
\hline & Citrumelo CPB 4475 & $6.80 \pm 0.01$ & $27.00 \pm 0.09^{*}$ & $7.90 \pm 0.01$ & $38.00 \pm 0.03^{*}$ & $9.09 \pm 0.02$ & $48.34 \pm 0.04 *$ \\
\hline & Cleopatra mandarin & $8.89 \pm 0.03$ & $20.85 \pm 0.10^{*}$ & $8.57 \pm 0.08$ & $43.14 \pm 0.21^{*}$ & $6.55 \pm 0.04$ & $39.08 \pm 0.11^{*}$ \\
\hline \multirow{3}{*}{$\begin{array}{l}\text { MDA } \\
\text { (nmol/g } \\
\text { fresh } \\
\text { tissue) }\end{array}$} & Carrizo citrange & $37.09 \pm 1.46$ & $24.74 \pm 1.35^{*}$ & $14.90 \pm 0.85$ & $18.42 \pm 1.33^{*}$ & $27.31 \pm 2.92$ & $16.93 \pm 0.70^{*}$ \\
\hline & Citrumelo CPB 4475 & $21.99 \pm 1.18$ & $21.55 \pm 1.47$ & $22.04 \pm 0.50$ & $20.65 \pm 0.51$ & $23.75 \pm 0.84$ & $20.45 \pm 1.55$ \\
\hline & Cleopatra mandarin & - & - & $21.34 \pm 0.96$ & $21.02 \pm 0.76$ & $24.83 \pm 0.47$ & $25.21 \pm 0.74$ \\
\hline \multirow{3}{*}{$\begin{array}{l}\text { ABA } \\
\text { (ng/g } \\
\text { fresh tissue) }\end{array}$} & Carrizo citrange & $37.20 \pm 9.35$ & $29.05 \pm 4.99$ & $53.55 \pm 2.32$ & $23.65 \pm 3.84^{*}$ & $91.37 \pm 8.31$ & $33.13 \pm 3.95^{*}$ \\
\hline & Citrumelo CPB 4475 & $78.75 \pm 7.51$ & $52.05 \pm 2.74^{*}$ & $40.70 \pm 1.85$ & $78.42 \pm 14.54^{*}$ & $157.40 \pm 7.38$ & $82.39 \pm 3.40^{*}$ \\
\hline & Cleopatra mandarin & $104.50 \pm 18.84$ & $90.50 \pm 3.16$ & $26.00 \pm 0.56$ & $22.00 \pm 2.30$ & $24.95 \pm 2.30$ & $13.30 \pm 2.15^{*}$ \\
\hline \multirow{3}{*}{$\begin{array}{l}\text { SA } \\
\quad(\mathrm{ng} / \mathrm{g} \\
\text { fresh tissue) }\end{array}$} & Carrizo citrange & $57.60 \pm 11.03$ & $74.90 \pm 9.05$ & $79.45 \pm 6.05$ & $75.20 \pm 2.66$ & $108.15 \pm 6.31$ & $57.15 \pm 18.54^{*}$ \\
\hline & Citrumelo CPB 4475 & $33.25 \pm 5.34$ & $55.35 \pm 6.32 *$ & $42.60 \pm 4.98$ & $54.25 \pm 11.49$ & $60.15 \pm 5.28$ & $62.20 \pm 11.59$ \\
\hline & Cleopatra mandarin & $67.20 \pm 4.88$ & $176.45 \pm 5.16^{*}$ & $116.10 \pm 7.92$ & $71.35 \pm 5.02 *$ & $79.60 \pm 9.02$ & $62.35 \pm 7.56$ \\
\hline
\end{tabular}

* Symbols followed with an asterisk denote statistical significance at $P<0.05$. Data in insets are normalized mean values \pm relative SE

Table 3 Chloride, malondialdehyde (MDA), abscisic acid (ABA) and salicylic acid (SA) contents in Carrizo citrange shoots after 2, 5 and 10 days of saline treatment

\begin{tabular}{|c|c|c|c|c|c|c|}
\hline & \multicolumn{6}{|c|}{ Time of treatment (days) } \\
\hline & \multicolumn{2}{|l|}{2} & \multicolumn{2}{|l|}{5} & \multicolumn{2}{|l|}{10} \\
\hline & Control & $60 \mathrm{mM} \mathrm{NaCl}$ & Control & $60 \mathrm{mM} \mathrm{NaCl}$ & Control & $60 \mathrm{mM} \mathrm{NaCl}$ \\
\hline $\mathrm{Cl}^{-}$(mg/g fresh tissue) & $1.68 \pm 0.03$ & $2.73 \pm 0.04^{*}$ & $1.72 \pm 0.08$ & $5.02 \pm 0.09 *$ & $1.15 \pm 0.04$ & $5.38 \pm 0.13^{*}$ \\
\hline MDA (nmol/g fresh tissue) & $16.48 \pm 1.49$ & $20.79 \pm 0.99$ & $18.41 \pm 2.08$ & $17.31 \pm 1.38$ & $27.30 \pm 1.35$ & $29.74 \pm 1.76$ \\
\hline ABA (ng/g fresh tissue) & $25.20 \pm 2.80$ & $30.07 \pm 3.87$ & $33.20 \pm 5.91$ & $9.60 \pm 1.40^{*}$ & $8.40 \pm 1.60$ & $11.33 \pm 0.40$ \\
\hline SA (ng/g fresh tissue) & $34.60 \pm 13.00$ & $27.73 \pm 6.82$ & $28.93 \pm 5.28$ & $37.80 \pm 5.24$ & $35.00 \pm 3.60$ & $56.73 \pm 12.91$ \\
\hline
\end{tabular}

* Symbols followed with an asterisk denote statistical significance at $P<0.05$. Data in insets are normalized mean values \pm relative SE

Table 4 Foliar damage, chloride and malondialdehyde (MDA) contents in Carrizo citrange shoots grown in medium supplemented or not with $0.2 \mathrm{mg} / \mathrm{l}$ of gibberellic acid and 6-benzylaminopurine. Data were recorded after 20 days of saline treatment

\begin{tabular}{|c|c|c|c|c|}
\hline & \multicolumn{4}{|l|}{ Treatment } \\
\hline & \multicolumn{2}{|l|}{+} & \multicolumn{2}{|l|}{-} \\
\hline & Control & $60 \mathrm{mM} \mathrm{NaCl}$ & Control & $60 \mathrm{mM} \mathrm{NaCl}$ \\
\hline Foliar damage $(\%)$ & $0.00 \pm 0.00$ & $72.90 \pm 1.10^{*}$ & $0.00 \pm 0.00$ & $68.00 \pm 0.20^{*}$ \\
\hline $\mathrm{Cl}^{-}$(mg/g fresh tissue) & $1.67 \pm 0.03$ & $4.71 \pm 0.12 *$ & $1.63 \pm 0.07$ & $5.23 \pm 0.12 *$ \\
\hline MDA (nmol/g fresh tissue) & $28.06 \pm 1.55$ & $33.24 \pm 0.69 *$ & $17.51 \pm 1.67$ & $18.35 \pm 1.98 *$ \\
\hline
\end{tabular}

* Symbols followed with an asterisk denote statistical significance at $P<0.05$. Data in insets are normalized mean values \pm relative SE

The lack of ABA accumulation within in vitro cultured shoots of citrus genotypes under stress conditions could be due to the fact that the triggering signal for increasing biosynthesis must occur in the roots and the lack of this tissue in our system makes impossible for this early signal to occur. It was also possible that hormone-signalling had taken place before 10 days of saline treatment, when first data of ABA concentration were recorded. To exclude this last possibility and to elucidate the early effects of salt stress on in vitro grown citrus shoots, the pattern of chloride concentration, MDA and hormone concentrations in CC shoots were determined after 2, 5 and 10 days of salt 
stress treatment. Chloride accumulation in shoots was again gradual throughout this short experimental period, but no differences were found in MDA, ABA or SA levels between control and salinized shoots after short saline treatment periods, which do not support a putative early ABA- or SA-dependent signalling pathway.

After analyzing all data, we can conclude that when shoots are cultured without a root system, all genotypes accumulate the same levels of chloride and exhibit similar leaf damage as a consequence of the imposition of a salt stress treatment. The lack of an increase in MDA levels in all genotypes, and the common patterns of hormonal signalling, in both short and long periods of study indicate that, under the same salt conditions and with the same level of leaf chloride intoxication, no biochemical differences exist among tolerant and sensitive genotypes. This points to the roots as a key organ not only as a filter of chloride ions but also as a signalling system in citrus.

Acknowledgments This work was supported by the Spanish Ministerio de Ciencia e Innovación and Universitat Jaume I/Fundació Bancaixa through grants no. AGL2007-65437-C04-03/AGR and P1IB2006-02, respectively. Hormone determinations were performed in the central facilities (Servei Central d'Instrumentació Científica, SCIC) of Universitat Jaume I. M. L-C was recipient of a fellowship from Universitat Jaume I.

\section{References}

Arbona V, Gómez-Cadenas A (2008) Hormonal modulation of Citrus responses to flooding. J Plant Growth Regul 27:241-250

Arbona V, Flors V, García-Agustín P, Jacas J, Gómez-Cadenas A (2003) Enzymatic and non-enzymatic antioxidant responses of Carrizo citrange a salt-sensitive citrus rootstock, to different levels of salinity. Plant Cell Physiol 44:388-394

Arbona V, Hossain Z, Lopez-Climent MF, Pérez-Clemente RM, Gómez-Cadenas A (2008) Antioxidant enzymatic activity is linked to waterlogging stress tolerance in citrus. Physiol Plant 132:452-466

Bañuls J, Serna MD, Legaz M, Primo-Millo E (1997) Growth and gas exchange parameters of citrus plants stressed with different salts. J Plant Physiol 150:194-199

Chapman HD (1968) The mineral nutrition of citrus. In: Reuther W, Batchelor LD, Webber HD (eds) The Citrus Industry, vol II. University of California, Oakland USA, pp 127-289

Christmann A, Moes D, Himmelbach A, Yang Y, Tang Y, Grill E (2006) Integration of abscisic acid signalling into plant responses. Plant Biol 8:314-325

Dodd IC, Egea G, Davies WJ (2008) Accounting for sap flow from different parts of the root system improves the prediction of xylem ABA concentration in plants grown with heterogeneous soil moisture. J Exp Bot 59:4083-4093

Durgbanshi A, Arbona V, Pozo O, Miersch O, Sancho JV, GómezCadenas A (2005) Simultaneous determination of multiple phytohormones in plant extracts by liquid chromatographyelectrospray tandem mass spectrometry. J Agric Food Chem 53:8437-8442
Gómez-Cadenas A, Tadeo FR, Primo-Millo E, Talon M (1998) Involvement of abscisic acid and ethylene in the response of citrus seedlings to salt shock. Physiol Plant 103:475-484

Gómez-Cadenas A, Arbona V, Jacas J, Primo-Millo E, Talon M (2002) Abscisic acid reduces leaf abscission and increases salt tolerance in citrus plants. J Plant Growth Regul 21:234-240

Hodges DM, DeLong JM, Forney CF, Prange RK (1999) Improving the thiobarbituric acid-reacting substances assay for estimating lipid peroxidation in plant tissues containing anthocyanin and other interfering compounds. Planta 207:604-611

Iglesias DJ, Levy Y, Gómez-Cadenas A, Tadeo FR, Primo-Millo E, Talon M (2004) Nitrate improves growth in salt-stressed citrus seedlings through effects on photosynthetic activity and chloride accumulation. Tree Physiol 24:1027-1034

Jia W, Youqun W, Shuqiu Z, Jianhua Z (2002) Salt-stress-induced ABA accumulation is more sensitively triggered in roots than in shoots. J Exp Bot 53:2201-2206

López-Climent MF, Arbona V, Pérez-Clemente RM, Gómez-Cadenas A (2008) Relationship between salt tolerance and photosynthetic machinery performance in citrus. Env Exp Bot 62:176-184

Montero E, Cabot C, Barcelo J, Poschenrieder C (1997) Endogenous abscisic acid levels are linked to decreased growth of bush bean plants treated with $\mathrm{NaCl}$. Physiol Plant 101:17-22

Moya JL, Tadeo FR, Gómez-Cadenas A, Primo-Millo E, Talón M (2002) Transmisible salt tolerante traits identified through reciprocal grafos between sensitive Carrizo and tolerant Cleopatra citrus genotypes. J Plant Physiol 159:991-998

Moya JL, Gómez-Cadenas A, Primo-Millo E, Talón M (2003) Chloride absorption in salt-sensitive Carrizo citrange and salttolerant Cleopatra mandarin citrus rootstocks is linked to water use. J Exp Bot 54:825-833

Munns R, Tester R (2008) Mechanisms of salinity tolerance. Annu Rev Plant Biol 59:651-681

Murashige T, Skoog F (1962) A revised medium for rapid growth and bioassays with tobacco cultures. Physiol Plant 15:473-497

Perl-Treves R, Perl A (2002) Oxidative stress: an introduction. In: Inze D, Montagu MV (eds) Oxidative stress in plants. Taylor \& Francis, London, pp 1-32

Romero-Aranda R, Moya JL, Tadeo FR, Legaz F, Primo-Millo E, Talon M (1998) Physiological and anatomical disturbances induced by chloride salts in sensitive and tolerant citrus: beneficial and detrimental effects of cations. Plant Cell Environ 21:1243-1253

Ruiz D, Martínez V, Cerdá A (1997) Citrus response to salinity: growth and nutrient uptake. Tree Physiol 17:141-150

Shalata A, Mittova V, Volokita M, Guy M, Tal M (2001) Response of the cultivated tomato and its wild salt-tolerant relative Lycopersicon pennellii to salt-dependent oxidative stress: the root antioxidative system. Physiol Plant 112:487-494

Sibole JV, Montero E, Cabot C, Poschenrieder CB (1998) Role of sodium in the ABA-mediated long-term growth response of bean to salt stress. Physiol Plant 104:299-305

Singh A, Saini ML, Behl RK (2004) In vitro screening of citrus rootstocks for salt tolerance. Indian J Genet Plant Breed 64:54-57

Walker RR, Sedgley M, Blesing MA, Douglas TJ (1984) Anatomy, ultrastructure and assimilate concentrations of roots of citrus genotypes differing in ability for salt exclusion. J Exp Bot 35: 1481-1494

Zhang YJ, Qian YQ, Mu X, Cai QG, Zhou YL, Wei XP (1998) Plant regeneration from in vitro-cultured seedling leaf protoplasts of Actinidia eriantha Benth. Plant Cell Rep 17(1998):819-821 